Rev. Saúde públ., S. Paulo, 24(5): 361-72, 1990

\title{
EPIDEMIA DE LEISHMANIOSE VISCERAL NO ESTADO DO PIAUÍ, BRASIL, 1980-1986*
}

\author{
Carlos Henrique N. Costa** \\ Humberto F. Pereira*** \\ Maurílio V. Araújo***
}

COSTA, C. H. N. et al. Epidemia de leishmaniose visceral no Estado do Piaur, Brasil, 1980-1986. Rev. Saúde públ., S. Paulo, 24: 361-72, 1990.

RESUMO: Analisou-se a epidemia de calazar ocorrida no Estado do Piauí, no período de 1980-1986. Os dados foram coletados pela SUCAM-Piauí, 6rgão do Ministério da Saúde para o controle de endemias, pela busca ativa na rede de assistência à saúde do Estado. A epidemia iniciou-se em municípios do centro e do norte, em 1980. No interior, ao contrário do período endêmico, quando predominou em áreas de maior altitude e clima semi-árido, a epidemia grassou nos vales de rios e em região mais úmida, de clima tropical. A capital do Piaú, Teresina, foi atingida em 1981, com pico epidêmico em 1984 e tendo sido responsável por mais de $60 \%$ dos 1.509 casos de todo o Estado. Foram feitas tentativas de controle pelo uso intensivo de inseticidas e eliminação de cães. Nas outras regiōes do Piaú, borrifadas intensivamente para o controle da doença de Chagas e da malária, a epidemia foi pouco importante e cedeu espontaneamente. Nem a casuística e nem a população flebotomínica de Teresina apresentaram variaçōes sazonais significativas, mas estiveram moderadamente correlacionadas entre si. Houve maior prevalência em menores de cinco anos, principalmente nos anos de maior incidência, e menor em maiores de 40 anos. A distribuição geográfica do processo epidêmico e a concomitância de seu início com seca prolongada acompanhada de emigração de pessoas e animais domésticos procedentes de regiōes endêmicas para aquelas epidêmicas, sugerem que estes movimentos migratórios desencadearam a epidemia. $O$ fato de o processo epidêmico ter cedido espontaneamente em áreas onde não se tentou o seu controle indica que não se pode atribuir apenas às medidas de controle o fim da epidemia. A partir da análise dos coeficientes de incidência específicos por faixa etária, é discutida a possiblilidade da progressiva redução na proporção de suscet́veis, determinada tanto por um grande número de infeç̧ōes assintomáticas como pela ocorrência de imunidade duradoura, ter contribuido para a extinção da epidemia.

DESCRITORES: Leishmaniose visceral, epidemiologia. Controle de insetos.

A leishmaniose visceral neotropical, zooantroponose causada pela Leishmania donovani chagasi acomete particularmente pré-escolares ${ }^{4}$. As publicações clássicas descrevem-na como endemia transmitida pelo flebótomo Lutzomyia longipalpis, que predomina nas áreas rurais de clima semi-árido e que tem como reservatórios o cão e a raposa ${ }^{2,20}$. Nos últimos anos, entretanto, tem se registrado a sua presença em centros urbanos, com características de epidemias ${ }^{9,48}$, como ocorre com o calazar indiano ${ }^{44}$.

O Estado do Piauí, onde a doença é conhecida desde 1934, é um dos principais focos da doença no Brasil ${ }^{6,46}$. A partir de 1980 observou-se nesse Estado uma epidemia que atingiu vasta extensão de seu território, concentrando-se especialmente na área urbana da capital, Teresina. Assim, pois, no presente trabalho foram analisadas as informaçð̃es dos serviços de saúde locais, com o objetivo de investigar os fatores que podem ter favorecido a ocorrência desse surto epidêmico, como tentativa de compreensão das recentes modificações epidemiológicas da leishmaniose visceral verificadas no Brasil.

\section{MATERIAL E MÉTODO}

\section{Espaço Geográfico}

O Estado do Piauí, localizado no Nordeste Ocidental brasileiro, está dividido em 116 municípios e 11 microrregióes homogêneas ( $\mathrm{MH})$. Apresenta altitudes mais elevadas, em torno de $600 \mathrm{~m}$, a leste, na serra do Ibiapaba na fronteira com o Estado do Ceará, e no sudeste e sul, rebaixando-se no

\footnotetext{
* Apresentado no XIII Congresso da Sociedade Brasileira de Medicina Tropical, Curitiba, 1987.

* Department of Tropical Public Health, Harvard School of Public Health, 667 Huntington Avenue, Boston-MA, 02115. USA:

* * Diretoria Regional da Superintendência de Campanhas de Saúde Pública no Piaú — 64000 - Teresina, PI — Brasil.
} 
sentido da Planície Parnaibana, para o norte e oeste. O Parnaíba é o único grande rio perene, estabelecendo todo o limite oeste. Seus afluentes principais, Gurguéia e Canindé, ao sul e Poti, e Longá, no centro e norte, são intermitentes durante a estação seca, deixando grandes coleçōes de água estagnada. O clima é quente, com temperaturas médias oscilando entre $33^{\circ} \mathrm{C} \mathrm{e} 22^{\circ} \mathrm{C}$. A presenta um período seco bem delimitado e chuvas de final de verão e outono. Segundo Koppen, trata-se de clima tropical com chuvas de verão ao norte (Aw), tropical com chuvas máximas no outono a oeste e sul (Aw') e semi-árido quente com inverno seco a sudeste (Bsh). No noroeste e no sul as isoietas são superiores a $1.200 \mathrm{~mm}$ e no sudeste inferiores a 800 $\mathrm{m} \mathrm{m}^{17}$ (Fig. 1-1). As secas são periódicas, acompanhadas de migraçōes humanas e de animais domésticos em sentido oeste, em direção às cidades ou aos vales dos rios, para onde é levado o gado bovino. A última seca ocorreu entre 1978 e $1983^{11,37}$. A vegetação dominante é a savana, com caatinga no semi-árido. A mata ciliar acompanha o curso dos rios e a noroeste surgem as matas de palmáceas de transição para a floresta equatorial amazônica ${ }^{32,43}$.

Em 1980 foi recenseada uma população de 2.140.066 habitantes ${ }^{36}$, predominantemente rural, mais concentrada no norte e oeste. A urbanização acentuada acompanha-se do esvaziamento rural. A economia é decadente, calcada na agricultura de subsistência consorciada com o latifúndio, na pecuária extensiva e na produção extrativa vegetal. Nos centros urbanos a renda origina-se basicamente do comércio e de empregos públicos ${ }^{16,41}$.

Teresina, capital do Piauí, está localizada na confluência dos rios Parnaíba e Poti, com um clima quente e úmido ${ }^{17}$ (Fig.1-1). Contava com 339.264 habitantes em 1980 , com elevado crescimento demográfico $(6,5 \% / \text { ano })^{36}$ e taxa migratória positiva de $35,6 /$ ano entre 1970 e $1980^{12}$. Tal regime demográfico é, em grande parte, fruto de imigrações conseqüentes à baixa produtividade e contradições fundiárias do campo e às secas periódicas ${ }^{1,12}$. E pontilhada por lotes vazios e quintais bem arborizados e cercada por grandes favelas, ocupadas basicamente por desempregados e subempregados muito pobres. Os principais locais de assentamento de migrantes, na época da epidemia, localizavam-se nas periferias das áreas urbanas sul e nordeste.

\section{Métodos de Análise}

Foram analisadas as informaçōes referentes ao calazar no Estado do Piauí, registradas na Diretoria Regional da Superintendência de Campanhas de Saúde Pública no Piauí (SUCAM-PI), órgão do Ministério da Saúde para o controle de endemias, no período de 1971 a 1986. Os casos humanos registrados no período de 1971 a 1980 foram obtidos através: da revisão de prontuários dos principais hospitais de Teresina onde eram feitos exames parasitológicos de aspirado de medula óssea*; dos registros próprios da SUCAM-PI, onde tamberm eram feitas pesquisas diretas de Leishmania na medula óssea; e de casos diagnosticados apenas a partir de história clínica e exame físico e notificados pelas unidades de saúde da Fundação Serviços Especiais de Saúde Pública, do interior do Estado. Em 1981, após a constatação da epidemia, a SUCAM-PI iniciou busca ativa de casos em toda a rede hospitalar pública e privada do Estado. Os critérios de diagnóstico foram a presença de sinais e sintomas da doença ou de parasitas na medula óssea, e, quando este exame era negativo, a reatividade dos testes de imunofluorescência indireta (IFI) realizados no laboratório de parasitologia da Universidade Federal do Piauí. Foram incluídos alguns pacientes que tiveram ambos os exames laboratoriais negativos para calazar mas cuja sintomatologia cedeu com a terapêtica com antimoniato de N-metil-glucamina. No início de 1982 a SUCAM-PI começou a pesquisa entomologica, caracterizada pela pesquisa semestral de flebótomos no interior das residências e no peridomicílio de todos os bairros de Teresina, realizada por equipe dirigida por técnico devidamente treinado e responsável pela identificação dos exemplares capturados. Nesse mesmo ano foi iniciado o inquérito canino, entendido como o exame sorologico (IFI) semestral de todos os cães domésticos da cidade.

As tentativas de controle da doença começaram em Teresina em setembro de 1981. Inicialmente foi feita a borrifação domiciliar de toda a cidade com hexacloroclohexano (BHC), posteriormente com diclorodifeniltricloroetano (DDT) e, finalmente, a aspersão ambiental com o derivado organofosforado Sumithion. No interior houve apenas um ciclo de borrifação em alguns municípios selecionados. Em 1982 foi começada a eliminação sistemática de cães vadios ou soro-reagentes para L.d.chagasi. No centro e norte do Estado, a SUCAM-PI fazia borrifaçōes com DDT, para o combate à malária, apenas nas localidades onde havia casos autóctones ou a possibilidade de transmissāo (borrifações focal e preventiva, respectivamente) (Fig. 1-3). No sudeste, de 1980 a 1984, foi executada a fase de ataque à doença de Chagas, usando-se piretróides nos domicílios e periodomicílios da zona rural de todos os municípios da região. No sul e sudeste, desde 1975, faziam-se borrifaçōes focais e preventivas para o controle da malária e, em 1984, foi iniciada a fase de ataque à doença de Chagas em alguns municípios da área (Fig. 1-4).

Os municípios piauienses foram classificados de acordo com o coeficiente de incidência acumula-

\footnotetext{
* Comunicação pessoal de J. T. Andrade e T. J. O. Fortes
} 


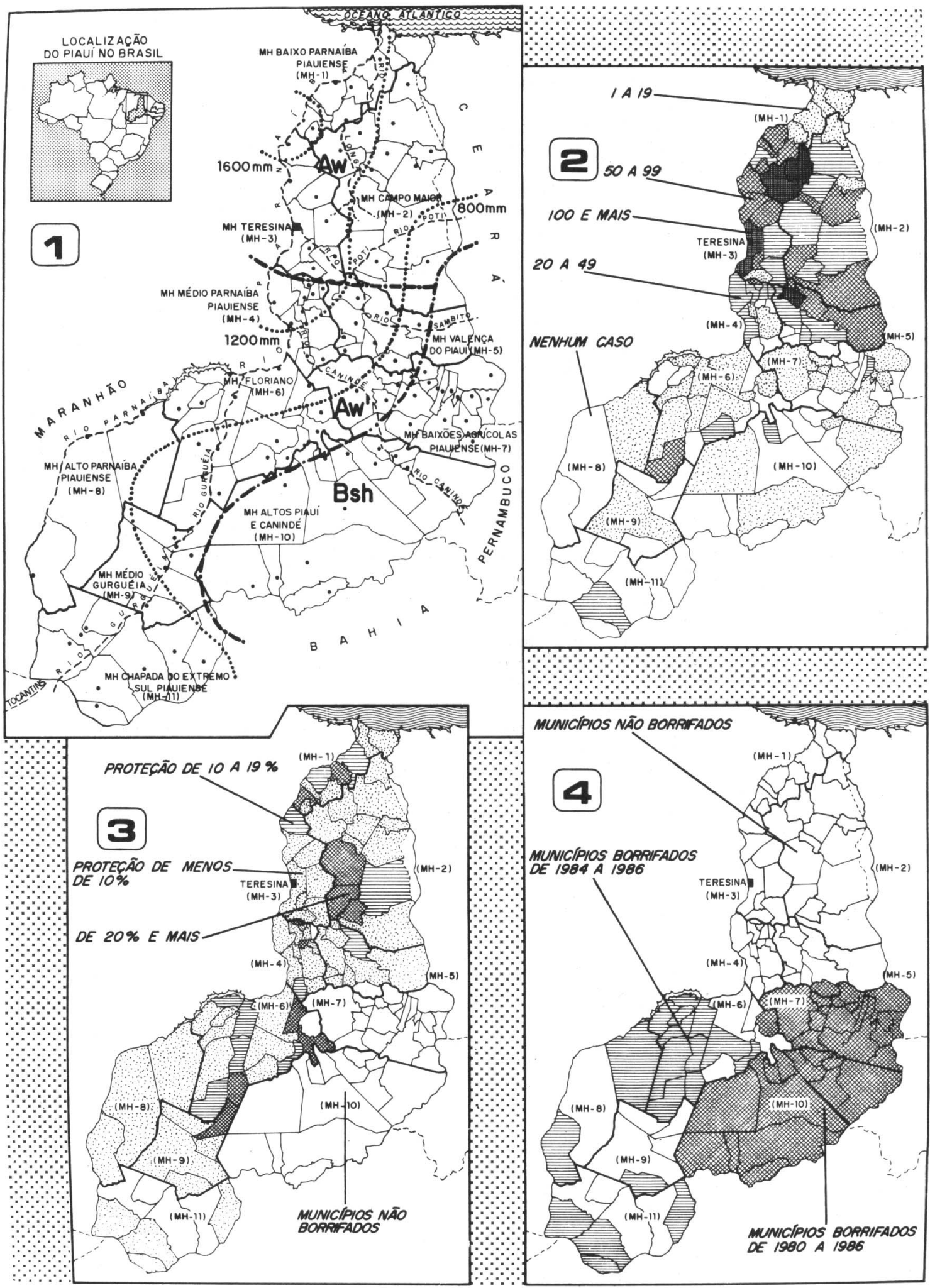

Fig. 1 - Mapa do Estado do Piauí. No mapa 1, a divisão por municípios e por microrregiōes homogêneas, os rios principais, as isoietas e os tipos climáticos (Koppen). No mapa 2, os coeficientes de incidência acumuladas por cem mil habitantes por município. No mapa 3 , os níveis de proteção contra a malária por município descritos no texto. No mapa 4 , os tipos de borrifação contra a doença de Chagas por município. 
do (CI) de calazar (mais de 100/100 000 habitantes, de 50 até $99 / 100000$, de 20 até 49/100 000, de um até $19 / 100000$ e nenhum caso). Foram também classificados segundo a parcela da população que teve suas casas aspergidas com DDT em cada ciclo de borrifação focal ou preventiva para o controle da malária. Foi somado o número de residências desinsetizadas por municípios em cada semestre, estimado o número total de ocupantes dessas moradias, calculadas as proporções das populaçōes municipais protegidas e calculadas as médias semestrais destas proporç̋̃es entre os anos de 1980 e 1985 (20\% e mais, de 10 a $19 \%$ e menos de $10 \%)$. Comparou-se a incidência da doença com os níveis de proteção conferidos por inseticidas e com os tipos de rociamento utilizados. $\mathrm{OCI}$ foi calculado para todo o Estado, todas as $\mathrm{MH}$, municípios e nas regiões urbanas e rurais e para cinco áreas urbanas de Teresina. O cálculo do $\mathrm{CI}$ foi feito a partir do total de casos registrados na SUCAM-PI. A população de referência foi aquela estimada para primeiro de julho de 1983 (Piauí, micro-regiōes e Município de Teresina e interior). Para as áreas de Teresina, utilizou-se como população de referência aquela recenseada pela SUCAM-PI em 1985 e a estimada para o Centro da Cidade para $1985^{51}$. Para os demais municípios foi usada a população recenseada em 1980. A pluviometria, para análise da sazonalidade, foi obtida junto à estação meteorológica do aeroporto de Teresina. Foi usado o teste do Qui Quadrado para análise da distribuição dos casos de menores de quatro anos, por ano, e da distribuição por sexo e faixa etária. Foi utilizada a regressão linear simples para a determinação do coeficiente de correlação entre o número de casos e a proporção de casas infestadas pela $L u$. longipalpis.

\section{RESULTADOS}

No período de 1971 a 1979 a leishmaniose visceral apresentava-se como uma endemia no Piauí e a maioria dos casos era notificada como procedente de Teresina. A maioria dos casos do interior era originada do semi-árido do sudeste do Estado. A Figura 1-2 e a Tabela 1 sintetizam a casuística do Estado no período de 1971 a 1986.

A epidemia teve início em 1980, com o registro de 16 casos. Destes, 11 eram procedentes do interior e vinham dos vales dos rios do norte e do centro do Estado. Concentrou-se nos municípios e MH atravessados pelo curso médio e inferior dos rios Poti e seu afluente Sambito e rio Longá e seus afluentes Maratoã e Piracuruca. Aí atingiu o ápice no ano de 1985. Foram relativamente baixos os $\mathrm{CI}$ das $\mathrm{MH}$ do sudeste e do oeste, regiões onde o calazar era mais prevalente antes da epidemia. O CI urbano foi maior que o rural em $64 \%$ dos municípios do norte (26/41) e em $92 \%$ dos municípios do sul e do sudeste $(24 / 25)$. Em Teresina a epidemia começou no ano de 1981 com o registro de 55 casos, a maioria procedente dos bairros novos, de assentamento de migrantes, nas áreas sul e nordeste da cidade e apenas no ano seguinte atingiu a área norte, de ocupação antiga (Tabela 2).

Quase nenhum dos dez municípios, cuja borrifação focal ou preventiva com DDT protegeu mais de $20 \%$ da população, teve $\mathrm{CI}$ acumulado maior que 50/100.000 nos sete anos de epidemia. Em todos os quatro municípios cujos $\mathrm{CI}$ acumulados foram maiores que $100 / 100000$ habitantes a proteção com borrifação focal ou preventiva não excedeu ao índice de $10 \%$ da população (Fig. 1-3). Na área

\section{TABELA 1}

Número de casos de calazar, coeficiente de incidência e predominância urbana segundo as regiões, Piauí, 1971-1986

\begin{tabular}{|c|c|c|c|c|c|c|c|c|c|c|c|c|c|c|c|c|c|c|c|}
\hline \multirow{2}{*}{ Regiōes } & \multicolumn{16}{|c|}{ Anos } & \multirow[b]{2}{*}{$\begin{array}{c}\text { Total } \\
1980-1986\end{array}$} & \multicolumn{2}{|l|}{ Coeficiente } \\
\hline & 71 & & 73 & 74 & $\pi$ & 76 & 77 & 78 & 79 & 80 & 81 & 82 & 83 & 84 & 85 & 86 & & $\begin{array}{c}\text { de } \\
\text { Incicância* }\end{array}$ & $\begin{array}{l}\text { Predominåncia } \\
\text { Urbana }\end{array}$ \\
\hline $\begin{array}{l}\text { Microrregioes homogêneas } \\
\text { - Baixo Parnaíba Piauiense } \\
\text { - Campo Maior } \\
\text { - Teresina } \\
\text { - Médio Parnaíba Piauiense } \\
\text { - Valença do Piauí } \\
\text { - Floriano } \\
\text { - Baixoes Agrícolas Piauienses } \\
\text { - Alto Parnaíba Piauiense } \\
\text { - Médio Gurguéia } \\
\text { - Altos Piaú e Canindé } \\
\text { - Chapadas do Extremo Sul do } \\
\text { Piauiense } \\
\text { Sem Endereço (Interior) } \\
\text { Teresina } \\
\text { Interior } \\
\text { Piauí }\end{array}$ & $\begin{array}{l}- \\
\overline{2} \\
- \\
- \\
\overline{1} \\
- \\
- \\
-\end{array}$ & $\begin{array}{l}- \\
3 \\
- \\
- \\
- \\
- \\
- \\
- \\
- \\
\end{array}$ & $\begin{array}{l}- \\
3 \\
- \\
- \\
- \\
- \\
1\end{array}$ & $\begin{array}{l}- \\
5 \\
- \\
- \\
- \\
1 \\
- \\
- \\
-\end{array}$ & $\begin{array}{l}- \\
\overline{1} \\
- \\
- \\
- \\
- \\
- \\
-\end{array}$ & $\begin{array}{l}- \\
6 \\
1 \\
- \\
- \\
- \\
- \\
- \\
1\end{array}$ & $\begin{array}{l}- \\
2 \\
- \\
- \\
- \\
- \\
-\end{array}$ & $\begin{array}{l}- \\
4 \\
- \\
1 \\
- \\
1 \\
- \\
-\end{array}$ & $\begin{array}{l}- \\
- \\
7 \\
- \\
- \\
- \\
- \\
\overline{1}\end{array}$ & $\begin{array}{l}- \\
8 \\
5 \\
- \\
3 \\
- \\
- \\
- \\
- \\
-\end{array}$ & $\begin{array}{r}5 \\
5 \\
56 \\
- \\
2 \\
2 \\
2 \\
- \\
- \\
1\end{array}$ & $\begin{array}{r}8 \\
12 \\
199 \\
1 \\
2 \\
1 \\
3 \\
\vdots \\
1 \\
2 \\
- \\
11 \\
194 \\
46 \\
240\end{array}$ & $\begin{array}{r}9 \\
41 \\
205 \\
7 \\
5 \\
2 \\
2 \\
- \\
- \\
- \\
10 \\
196 \\
83 \\
279\end{array}$ & $\begin{array}{r}17 \\
62 \\
339 \\
7 \\
7 \\
6 \\
2 \\
1 \\
- \\
4\end{array}$ & $\begin{array}{r}28 \\
66 \\
199 \\
10 \\
14 \\
8 \\
8 \\
1 \\
1 \\
3\end{array}$ & $\begin{array}{c}4 \\
37 \\
56 \\
3 \\
3 \\
3 \\
6 \\
- \\
- \\
5\end{array}$ & $\begin{array}{r}71 \\
231 \\
1.059 \\
28 \\
36 \\
20 \\
23 \\
2 \\
2 \\
15 \\
\\
1 \\
21 \\
974 \\
535 \\
1.509\end{array}$ & $\begin{array}{r}26 \\
60 \\
180 \\
26 \\
37 \\
14 \\
8 \\
7 \\
5 \\
7\end{array}$ & $\begin{array}{r}6 / 7 \\
9 / 13 \\
5 / 8 \\
7 / 9 \\
3 / 7 \\
7 / 9 \\
8 / 8 \\
1 / 1 \\
1 / 1 \\
5 / 7\end{array}$ \\
\hline
\end{tabular}

* Acumulado de 1980 a 1986/100 000 habitantes. Populaçăo de referência estimada para 1\%/07/83. Número de municípios onde o coeficiente de inciđência urbano foi maior que o coeficiente de incidência rural/todos
os municipios com casos. 


\section{TABELA 2}

Casos de calazar e coeficientes de incidência por área urbana, Teresina, agosto de 1981 a dezembro de 1986

\begin{tabular}{|c|c|c|c|c|c|c|c|c|}
\hline \multirow{2}{*}{$\begin{array}{l}\text { Áreas } \\
\text { Urbanas }\end{array}$} & \multicolumn{6}{|c|}{ Ano } & \multirow{2}{*}{ Total } & \multirow{2}{*}{$\begin{array}{l}\text { Coeficientes de } \\
\text { Incidência** }\end{array}$} \\
\hline & $1981^{*}$ & 1982 & 1983 & 1984 & 1985 & 1986 & & \\
\hline $\begin{array}{l}\text { Norte } \\
\text { Sul } \\
\text { Central } \\
\text { Nordeste } \\
\text { Sudeste }\end{array}$ & $\begin{array}{c}- \\
11 \\
5 \\
10 \\
2\end{array}$ & $\begin{array}{l}17 \\
71 \\
30 \\
60 \\
10\end{array}$ & $\begin{array}{r}24 \\
52 \\
18 \\
67 \\
3\end{array}$ & $\begin{array}{r}53 \\
54 \\
21 \\
137 \\
7\end{array}$ & $\begin{array}{r}43 \\
25 \\
26 \\
45 \\
6\end{array}$ & $\begin{array}{r}6 \\
19 \\
7 \\
11 \\
3\end{array}$ & $\begin{array}{r}143 \\
221 \\
102 \\
320 \\
29\end{array}$ & $\begin{array}{r}141 \\
187 \\
138 \\
690 \\
75\end{array}$ \\
\hline Teresina & 28 & 188 & 164 & 272 & 145 & 46 & 843 & 215 \\
\hline
\end{tabular}

* De agosto a dezembro.

* * Todos os casos de agosto de 1981 a dezembro de 1986/100 000 habitantes. Baseado em população de censo residencial feito pela SUCAM-PI em 1985 e em eqtimativa pela Prefeitura de Teresina em 1985.

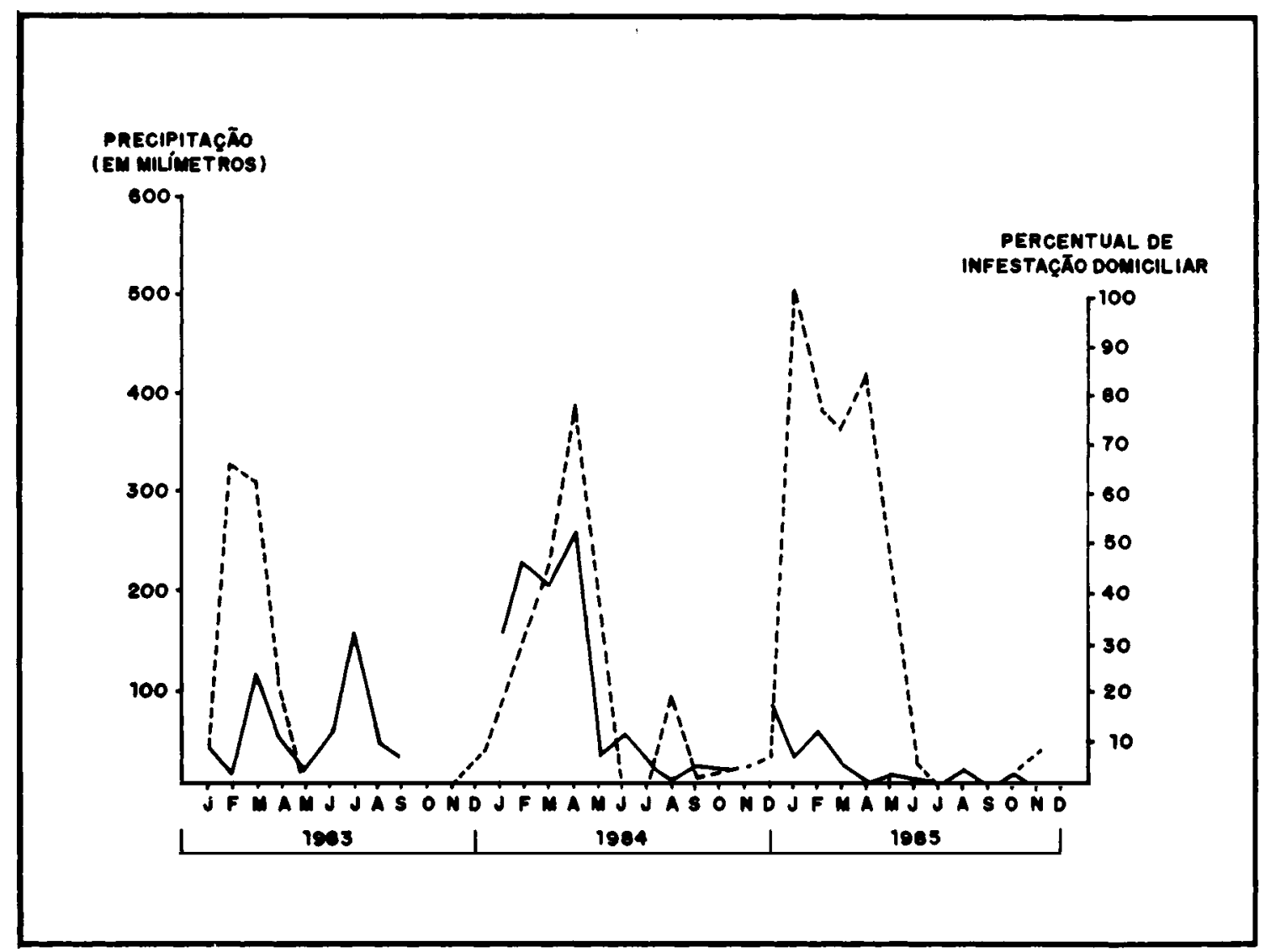

Percentual mensal de habitações com Lutzomyia longipalpis

----- - - Precipitação pluviométrica mensal

Fig. 2 - Precipitação pluviométrica e proporção da infestação domiciliar pela Lutzomyia longipalpis em Teresina, de janeiro de 1983 a novembro de 1985. 


\section{TABELA 3}

Números de casos de calazar e proporção de casas investigados com Lutzomyia longipalpis na área urbana de Teresina, por semestre, no período de janeiro de 1983 a junho de $1986^{*}$

\begin{tabular}{|c|c|c|c|c|c|}
\hline \multirow[t]{2}{*}{ Ano } & \multirow[t]{2}{*}{ Semestre } & \multirow[t]{2}{*}{$\mathrm{N}^{\mathbf{e}}$} & \multirow[t]{2}{*}{ casos } & \multicolumn{2}{|c|}{$\begin{array}{l}\text { Casas com } L u \text {. longipalpis } \\
\text { dentre as investigadas }\end{array}$} \\
\hline & & & & Ne & $\%$ \\
\hline 1983 & $\begin{array}{l}1^{\circ} \\
2^{\circ}\end{array}$ & $\begin{array}{l}67 \\
97\end{array}$ & & $\begin{array}{c}166 / 2.099 \\
37 / 416\end{array}$ & $\begin{array}{l}7,9 \\
8,9\end{array}$ \\
\hline 1984 & $\begin{array}{l}10 \\
2^{\circ}\end{array}$ & $\begin{array}{l}136 \\
136\end{array}$ & & $\begin{array}{c}308 / 1.452 \\
34 / 920\end{array}$ & $\begin{array}{r}21,2 \\
3,7\end{array}$ \\
\hline 1985 & $\begin{array}{l}1^{\circ} \\
2^{\circ}\end{array}$ & $\begin{array}{l}87 \\
62\end{array}$ & & $\begin{array}{l}42 / 1.030 \\
30 / 1.129\end{array}$ & $\begin{array}{l}4,1 \\
2,7\end{array}$ \\
\hline 1986 & $1^{\circ}$ & 22 & & $18 / 551$ & 3,3 \\
\hline
\end{tabular}

* $\quad r=0,55$

\section{TABELA 4}

Número e proporção de casos de calazar por idade e ano e coeficiente de incidência específico por faixa etária, Estado do Piauí, janeiro de 1982 a setembro de 1986

\begin{tabular}{|c|c|c|c|c|c|c|c|c|c|c|c|c|c|}
\hline \multirow{3}{*}{$\begin{array}{l}\text { Idade } \\
\text { (anos) }\end{array}$} & \multicolumn{8}{|c|}{ Ano } & & & & & \multirow{3}{*}{$\begin{array}{l}\text { Coeficiente de in- } \\
\text { cidência específico } \\
\text { por faixa etária* }\end{array}$} \\
\hline & \multicolumn{2}{|c|}{1982} & \multicolumn{2}{|c|}{1983} & \multicolumn{2}{|c|}{1984} & \multicolumn{2}{|c|}{1985} & \multicolumn{2}{|c|}{1986} & \multicolumn{2}{|c|}{ Total } & \\
\hline & $\mathrm{N}^{\mathrm{e}}$ & $\%$ & Ne & $\%$ & $\mathrm{~N}^{2}$ & $\%$ & № & $\%$ & $\mathrm{~N}^{\mathrm{e}}$ & $\%$ & $\mathrm{~N}^{2}$ & $\%$ & \\
\hline $\begin{array}{r}>1 \\
1-4 \\
\text { Sub-Total }^{* *} \\
5-19 \\
20-39 \\
\geq 40\end{array}$ & $\begin{array}{r}5 \\
98 \\
103 \\
83 \\
36 \\
15\end{array}$ & $\begin{array}{r}2,1 \\
41,3 \\
43,5 \\
35,0 \\
15,2 \\
6,1\end{array}$ & $\begin{array}{r}9 \\
114 \\
123 \\
86 \\
41 \\
11\end{array}$ & $\begin{array}{r}3,4 \\
43,7 \\
47,1 \\
32,9 \\
15,7 \\
4,2\end{array}$ & $\begin{array}{r}15 \\
198 \\
223 \\
123 \\
67 \\
16\end{array}$ & $\begin{array}{r}5,8 \\
46,2 \\
52,0 \\
22,7 \\
15,6 \\
3,7\end{array}$ & $\begin{array}{r}5 \\
120 \\
125 \\
95 \\
64 \\
19\end{array}$ & $\begin{array}{r}1,7 \\
39,6 \\
41,3 \\
31,3 \\
21,1 \\
6,3\end{array}$ & $\begin{array}{r}1 \\
21 \\
22 \\
32 \\
16 \\
6\end{array}$ & $\begin{array}{r}1,3 \\
27,6 \\
28,9 \\
42,1 \\
21,0 \\
7,9\end{array}$ & $\begin{array}{r}45 \\
551 \\
596 \\
419 \\
224 \\
67\end{array}$ & $\begin{array}{r}3,4 \\
42,2 \\
45,6 \\
32,1 \\
17,2 \\
5,1\end{array}$ & $\begin{array}{r}* * * \\
* * * \\
126 \\
48 \\
42 \\
18\end{array}$ \\
\hline Total & 237 & 100,0 & 261 & 100,0 & 429 & 100,0 & 303 & 100,0 & 76 & 100,0 & 1.306 & 100,0 & 61 \\
\hline
\end{tabular}

* Acumulado de janeiro de 1982 a setembro de 1986 por 100000 habitantes.

* * $\quad p<0,05$ aplicado à distribuição da doença em menores de quatro anos.

* * Não foram encontradas informações sobre a população com esta faixa etária.

onde a fase de ataque à doença de Chagas foi iniciada em 1980, quase nenhum município teve CI superior a 20/100 000. Entre aqueles municípios que entraram na fase de ataque à doença de Chagas em 1984 , só um teve CI maior que 20/100 000. Alguns municípios desse distrito da SUCAM, que não foram submetidos ao rociamento com inseticidas para o controle da doença de Chagas, apresentaram $\mathrm{CI}$ muito baixos ou não tiveram nenhum caso da doença (Fig. 1-4).

Não se observou variação sazonal importante. Verificaram-se menores médias do número de casos nos meses de fevereiro a abril e maior média no período de setembro a janeiro, com maior concentração em outubro. A proporção de casas infestadas por $L u$. longipalpis variou irregularmente com a precipitação pluviométrica, havendo período seco com elevados índices de infestação domiciliar. Contudo, o período de maior grau de infestação domiciliar coincidiu com o período chuvoso do início de 1985 (Fig. 2).

O número de casos humanos por semestre correlacionou-se positivamente com a proporção semestral de casas investigadas e infestadas por Lu. Longipalpis, mas esta correlação foi apenas moderada $(r=0,55)$ (Tabela 3 ). Os primeiro e segundo semestres de 1984 apresentaram a maior casuística. Entretanto, no segundo semestre a proporção de casas infestadas foi muito baixa, sugerindo que grande parte dos casos da área urbana de Teresina, naquele semestre, tenha sido infectada no primeiro semestre. 
TABELA 5

Número e proporção de casos de calazar por idade e sexo, Estado do Piauí, setembro de 1981 a dezembro de 1986*

\begin{tabular}{|c|c|c|c|c|c|c|c|c|c|c|c|c|c|c|c|c|c|c|}
\hline \multirow{2}{*}{$\begin{array}{l}\text { Idade } \\
\text { Sexo }\end{array}$} & \multicolumn{2}{|c|}{1} & \multicolumn{2}{|c|}{$1-4$} & \multicolumn{2}{|c|}{$5-9$} & \multicolumn{2}{|c|}{$10-14$} & \multicolumn{2}{|c|}{$15-19$} & \multicolumn{2}{|c|}{$20-29$} & \multicolumn{2}{|c|}{$30-39$} & \multicolumn{2}{|c|}{$40 \mathrm{e}+$} & \multicolumn{2}{|c|}{ Total } \\
\hline & No & $\%$ & $\mathrm{~N}^{2}$ & $\%$ & No & $\%$ & $\mathrm{~N}^{\mathrm{O}}$ & $\%$ & No & $\%$ & $\mathrm{~N}^{2}$ & $\%$ & $\mathrm{~N}^{2}$ & $\%$ & $\mathrm{~N}^{2}$ & $\%$ & $\mathrm{~N}^{2}$ & $\%$ \\
\hline Masculino & 24 & 50 & 308 & 54 & 156 & 61 & 64 & 60 & 70 & 76 & 131 & 77 & 70 & 78 & 63 & 85 & 893 & 63 \\
\hline Feminino & 24 & 50 & 263 & 46 & 98 & 39 & 42 & 40 & 24 & 24 & 39 & 23 & 18 & 22 & 11 & 15 & 519 & 47 \\
\hline Total & 48 & 100 & 571 & 100 & 254 & 100 & 106 & 100 & 101 & 100 & 170 & 100 & 88 & 100 & 74 & 100 & 1.412 & 100 \\
\hline
\end{tabular}

* $\mathrm{p}<0,001$


Fig. 3 - Modelo proposto para o processo endomo-epidêmico do calazar no Meio-Norte brasileiro. Em "A", o padrão endêmico clássico, em pés-de-serra do semi-árido, apresentando o cão e a raposa como reservatórios. Em "B" o fenômeno da seca acompanhado da migração de pessoas e animais para as cidades ou para os vales de rios. Em "C", a precariedade das condições de vida nas periferias urbanas propiciando a eclosão de surtos epidêmicos, tanto pela proliferação do vetor secundária à abundância das fontes de alimentos e à proximidade de criadouros, como pela circulação do agente etiológico a partir de cães e pessoas infectadas. Em "D", o padrão epidêmico rural dos vales dos rios, onde, nas escassas coleçōes de água, acumulam-se reservatórios domésticos e silvestres, outros animais domésticos e pessoas, infectadas e suscetíveis.

Os casos de calazar humano ocorreram em indivíduos de três meses até 93 anos de idade. Quarenta e seis por cento destes casos, em que a idade foi registrada, eram menores de cinco anos. O CI específico por faixa etária foi acentuadamente maior entre as crianças desta faixa etária e menor entre os adultos com mais de 40 anos. À medida em que era maior a casuística maior era a proporção 
de menores de cinco anos acometida (Tabela 4). Houve uma sensível predominância no sexo masculino, exacerbando-se progressivamente com o aumento da faixa etária (Tabela 5).

\section{DISCUSSÃO}

Apesar de reconhecida no Estado do Piauí, desde 1934, não existe nele registro de epidemia de leishmaniose visceral. Foi observado um maior número de casos no periodo de 1953 a $1962^{4,5}$, mas estes números são produto de investigação científica, ao contrário das informações referentes a outras épocas e dizem respeito, em sua maior parte, a municípios próximos à cidade de Sobral, no Estado do Ceará, sede dessas investigações ${ }^{27}$. A maioria dos casos da década de setenta foi registrada como procedente de Teresina mas, como apenas aí examinava-se aspirado de medula óssea para diagnóstico e não se fazia investigação epidemiológica para confirmação do local de procedência, é provável que muitos desses casos tenham sido oriundos de outras áreas. Quase todos os casos apontados como procedentes do interior, nesse período, vieram de regiōes de clima semi-árido, a sudeste e a leste, com clima Bsh (Koppen) ou com precipitação pluviométrica anual inferior a 800 $\mathrm{mm}$ e altitudes médias superiores a $200 \mathrm{~m}$. Esta distribuição é característica do calazar no Brasil, pois é no semi-árido do Nordeste onde é mais encontrado ${ }^{4,26}$. Nessas áreas o vetor é a $L u$. longipalpis ${ }^{30,50}$ e os principais reservatórios são o cão doméstico e a raposa Dusicyon (Lycalopex) vetulus $21,22,23,49$. A transmissão da doença ocorre principalmente em pés-de-serra e boqueirões, onde as condiçōes de umidade e vegetação propiciam um microclima adequado e o vetor é encontrado mais facilmente ${ }^{25,28}$. É muito provável que os casos do semi-árido piauiense tenham se originado de ecossistemas similares. Nos anos de epidemia houve uma sensível mudança no comportamento epidemiologico da doença. Predominou em áreas urbanas de clima tropical Aw e Aw' (Koppen), onde as isoietas são superiores a $1.200 \mathrm{~mm}$, em altitudes inferiores a $200 \mathrm{~m}$, nos vales dos rios Parnaiba, Longá e Poti-Sambito, após dois anos de uma seca que se prolongou até 1983.

A ocorrência de epidemias de doenças infecciosas depende da concomitância de três fatores: grau de contato entre infectantes e suscetíveis adequado para a transmissão do agente etiológico, presença de fontes de infecção e proporção suficiente de suscetíveis nessa população ${ }^{35,39}$. No caso das doenças mataxênicas, a dinâmica populacional dos vetores adquire especial importância, à medida em que representa um dos principais fatores que determina o grau de contato entre infectantes e suscetíveis.

Apesar de não se dispor de informações sobre a população de Lu. longipalpis no interior do Estado do Piauí ou no período anterior ao processo epidêmico, algumas informações disponíveis permi- tem considerações acerca do papel desempenhado pelo uso de inseticidas nesta epidemia. Parece claro que as campanhas de borrifação para o controle da doença de Chagas e da malária contribuíram efetivamente para a distribuição geográfica do surto epidêmico no Estado, o que está de acordo com as primeiras observações acerca do uso de inseticidas para o controle da leishmaniose visceral no Brasil ${ }^{3,29}$. Estas evidências estão fundamentadas nas observaçōes que nas regiōes borrifadas para o controle da doença de Chagas, no semi-árido do sudeste do Piauí, o CI foi baixo, concentrando-se os casos nas áreas urbanas não borrifadas. Nas regiões submetidas à aspersão com inseticidas para o controle da malária o CI só foi elevado nos municípios onde menor parcela da população era płotegida pelo uso de DDT. Entretanto, a constatação de que em alguns municípios do leste, submetidos a limitada borrifação focal ou preventiva e que não apresentaram Cl elevados, e que em todo o interior do Estado o processo epidêmico cedeu, mesmo na ausência de medidas especificamente destinadas ao seu controle, indicam que outros fatores, além da interferência na população vetorial, participaram da distribuição desta epidemia de leishmaniose visceral no Piauí.

$O$ início do surto epidêmico pode ser atribuído a dois fenômenos de natureza distinta. De um lado é lícito especular-se se o incremento na densidade populacional, ou a ocorrência de populaçð̃es morfológicas de $L u$. longipalpis dotadas de maior intropofilia ${ }^{52}$ antecedendo a epidemia, teriam permitido maior grau de contato entre os suscetíveis e as fontes de infecção pré-existentes. Contudo, apesar de saber-se da coexistência de populaçōes morfologicamente distintas de Lu. longipalpis, em Teresina*, não se conhece as suas variaçōes populacionais antes e após a epidemia. Além disso, não se observou variações sazonais significativas na população flebotomínica em Teresina, nem houve correlação estreita entre o encontro de flebótomos nos domicílios e a casuística humana que permitissem esta hipótese. Isto indica que, pelo menos naquela capital, o aumento da probabilidade de contatos mediante a população vetorial, antes da epidemia, não parece ter contribuído decisivamente para o início do surto. Por outro lado, como ocorreram importantes migraçðes de pessoas e animais domésticos de regiões endêmicas para as regiőes onde grassou a epidemia, é possível suporse que tenham sido esses migrantes quem introduziram a $L . d$. chagasi em proporção suficiente para a eclosão do surto. $O$ período de seca que atingiu o Piauí e o Ceará entre 1978 e 1983 foi suficiente para comprometer gravemente as culturas de subsistência do pequeno produtor rural ${ }^{11,34,37}$ e as pastagens naturais. Como conseqüência de secas desse porte estabelecem-se correntes migratorias a par-

\footnotetext{
* Dados fornecidos pela SUCAM - Não publicados
} 
tir das regiões daqueles dois Estados mais atingi$\operatorname{dos}^{33}$, justamente aquelas onde o calazar é endêmi$\mathrm{co}^{6,8}$. Tais migraçōes destinam-se para Teresina onde as populações fixam-se em favelas na sua periferia, ou para os vales dos rios que, na seca, permanecem com coleções de água estagnada e onde a população ribeirinha, vaqueiros, cães, gado bovino e animais silvestres aglomeram-se temporariamente. Em ambas as circunstâncias, as migraçōes criam condições adequadas para a eclosão de surtos epidêmicos, ao propiciarem o contato de indivíduos suscetíveis, seja com fontes de infecção humana, seja com reservatórios domésticos nas cidades, ou com reservatórios silvestres nas áreas rurais. Deane ${ }^{20}$ e Alencar ${ }^{5}$ já haviam salientado a importância das secas na ocorrência de leishmaniose visceral no Nordeste do Brasil. Apesar do calazar urbano já ser bem conhecido neste país ${ }^{727}$, a sua presença em larga escala, em centros urbanos maiores, sob a forma de epidemia, é recente, conforme ocorreu em São Luis 9 , Santarém ${ }^{48}$, Fortale$\mathrm{za}^{*}$, Salvador* e Rio de Janeiro ${ }^{42}$. É provável que tenha se verificado nessas cidades o mesmo processo secundário às secas, de introdução de fontes de infecção na presença de Lu. longipalpis, tal como ocorreu em Teresina, e justifique a expansão do calazar no Brasil ${ }^{42}$. Deane e Deane ${ }^{24,27}$ haviam investigado e discutido o papel do homem como reservatório de $L$. $d$. chagasi. São necessários, entretanto, novos estudos acerca do potencial de transmissão do ser humano antes de se tecer paralelos entre estas epidemias brasileiras e as epidemias de calazar do tipo indiano.

A presença de um contingente significativo de pessoas suscetíveis proporcionou as condiçōes necessárias para a manifestação deste surto epidêmico do Piaur. Esta afirmativa pode ser compreendida a partir da análise da distribuição dos CI específicos por faixa etária durante os anos da epidemia. Os dados sugerem que a maior incidência no grupo de menor idade depende de maior susceptibilidade e não de maior exposição ao agente etiológico. Na verdade, ao revelarem que a participaçăo proporcional de menores de cinco anos na casuística global aumentou, em detrimento de outros grupos etários, quando maior era a incidência da doença na população geral, indicam que as crianças só ficam mais expostas que as pessoas mais velhas quando os vetores $e$ as fontes de infecção aumentam e penetram no seu restrito ambiente.

Esta maior susceptibilidade pode ser explicada por uma imunodepressão induzida pela desnutrição ${ }^{19}$, uma vez que são justamente os préescolares as suas maiores vítimas ${ }^{10}$. Os trabalhos de Badaró e col. ${ }^{14,15}$ demonstram com clareza o papel desempenhado pela desnutrição na susceptibilidade à infecção pela $L$. d. chagasi e à doença.

\footnotetext{
* Dados fornecidos pela SUCAM - Não publicados
}

Seus dados não explicariam, entretanto, o fato da leishmaniose visceral no Piauí ter incidido proporcionalmente muito menos no grupo com mais de 40 anos que na faixa de 20 a 39 . Isto reafirma a hipótese de ocorrer a presença de imunidade duradoura no calazar 13,40 . Entretanto, a pequena casuística registrada antes do ciclo epidêmico e o baixo $\mathrm{CI}$ verificado durante a epidemia não podem justificar repercussões tão significativas sobre a distribuição etária durante o surto epidêmico. É necessário e suficiente que se postule ter havido grande contingente de infecções oligossintomáticas ou assintomáticas, seguidas de imunidade duradoura, muito maior que o número de casos que tem sido notificado no Piauí. Não foi possível o desenvolvimento desta hipótese a partir de modelos matemáticos de epidemias, em função de não se ter tido acesso a algumas variáveis, necessárias para a aplicação desses modelos. Apesar de não se poder contar com registros representativos da situação do calazar em épocas passadas, é possível especular-se a ocorrência de uma epidemia há mais de 40 anos, que teria imunizado grande parte da população com esta faixa etária, e é sugestiva a hipótese da epidemia aqui apresentada, ter cedido em função do acúmulo de pessoas imunes e redução do número de suscetíveis. Este mesmo raciocínio pode justificar porque a epidemia não foi importante nos municípios endêmicos situados no sopé ocidental do Ibiapaba, onde seria reduzido o número de suscetíveis. No Piauí, o número de infecções assintomáticas ou oligossintomáticas foi, provavelmente, muito maior que a proporção de 18,5 infectados para cada doente, verificada no Estado da Bahia ${ }^{14}$ ou que as proporçōes encontradas na Europa ${ }^{45}$ ou na África ${ }^{38}$. Enquanto os dados desses trabalhos eram frutos do exame cuidadoso de pacientes para estudos, os casos do Estado do Piauí, apesar dos critérios diagnósticos satisfatórios, foram notificados por uma precária rede de serviços de saúde, onde nem sempre os médicos estavam familiarizados ou atentos ao quadro clínico da protozoose.

A diferença na incidència entre os sexos já foi observada e formulada a hipótese da existência de um fator ligado ao sexo ou à exposição ${ }^{2}$. O fato desta diferença aumentar com a idade a partir dos dois anos e acentuar-se abruptamente na adolescência sugere que uma possível razão seja a maior área corporal exposta à picada dos vetores nos homens que nas mulheres. No nordeste do Brasil, em virtude das temperaturas elevadas, trabalhadores e crianças do sexo masculino não costumam usar camisa no dia-a-dia, ao passo que as mutheres permanecem com o tronco protegido. Mesmo sem se ter observado controle genético sobre a infecção em pacientes ${ }^{13}$, as observaçōes efetuadas em camudongos infectados com $L$. donovani ${ }^{18} \mathrm{e}$ os dados aqui discutidos indicam que também deve ser investigada a existência de modulação geneticamente determinada e ligada ao sexo na susceptibilidade à leishmaniose visceral. 
As informações discutidas no presente trabalho são oriundas de sistemas mais voltados à assistência à saúde que dirigidas à pesquisa. Não foram registradas algumas informações valiosas e nem existem informações consistentes referentes ao periodo anterior à epidemia. Trata-se de um estudo de prevalência que lidou com dados retrospectivos e que algumas vezes utilizou correlação ecológica para análise. As conclusões são, mesmo assim, de interesse, merecendo confirmação através de novos estudos. Descreveu-se uma epidemia de calazar que apresentou distribuição geográfica distinta dos períodos endêmicos, quando predominou em cidades e em áreas rurais de clima tropical mais úmido. Isto indica que deve ser mais estudada a ecologia da leishmaniose visceral nas cidades e em áreas de transição geográfica entre florestas úmidas e cerrados mais secos. É necessário verificar-se a importância de diferentes fatores desencadeadores de surtos epidêmicos, tais como as variaçōes das populações do vetor, a introdução de casos novos e a imunidade de grupo, situando-se aí o papel desempenhado pelas migrações ruraisurbanas e rurais-rurais. De posse destes esclareci- mentos é possível a verificação da hipótese sintetizada na Figura 3. As informações que sugerem a presença de imunidade duradoura após a exposição à $L$. $d$. chagasi são consistentes e estimulam a procura por vacinas. A aparente presença de um elevado contingente de infecções assintomáticas indica que se deve considerar esta doença em portadores de síndrome de imunodeficiência adquirida oriundos de regiōes endêmicas, uma vez que o calazar pode se manifestar como infecção oportunista em portadores desta síndrome $e^{31,47}$. O problema da maior prevalência entre homens que em mulheres permanece em aberto. A metodologia de controle do calazar utilizada no Brasil merece reavaliação para o pronto controle destes surtos epidêmicos de ampla distribuição geográfica.

\section{AGRADECIMENTOS}

Ao Prof. Philip D. Marsden pelas sugestões apresentadas, ao Sr. Adalberto Borges pela confecção das ilustrações.

COSTA, C. H. N. et al [Visceral leishmaniasis epidemic in Piaui State, Brazil, 1980-1986]. Rev. Saĺde públ., S. Paulo, 24: 361-72, 1990.

ABSTRACT: The kala-azar epidemic in the State of Piaur 1980-1986 is analyzed on the basis of the data collected by SUCAM Piaú. The outbreak began in towns of central and northern Piauí in 1980. In contrast what has happened in endemic periods in which the disease occurred in areas of higher altitude and semi-arid climate, the epidemic developed in humid tropical river valleys in rural zones. The epidemic was worst in the towns. The state capital, Teresina, hit in 1981, reached the epidemic peak in 1984 and accounted, for more than $60 \%$ of the 1,509 cases in the state. The epidemic was not substantial in those regions sprayed to combat malaria and Chagas' disease. While control in Teresina was attempted through intensive use of insecticides, the outbreak gave way spontaneously in rural areas. Neither the number of cases nor the phlebotomine population of Teresina presented significant seasonal variations but were moderately correlated. There was greater prevalence in children of 5 years of age or less, especially during the peak epidemic years, and much lesser prevalence in adults over 40 years of age. The geographical distribution of the epidemic process and its beginning, concommitant with a prolonged drought with its accompanying migration of people and domestic animals from endemic to epidemic regions, suggests that migration unleashed the epidemic. The fact that the epidemic process spontaneously relinquished its hold in areas where no control was attempted, indicates that the end of the epidemic cannot be attributed solely to measures of control. An analysis of the coefficients of specific incidence within age groups sparks the discussion about the possibility that progressive reduction of susceptibility (determined by the great number of assymptomatic infections as well as by long-lasting immunity) contributed to the extinction of the epidemic.

KEYWORDS: Leishmaniasis, visceral, epidemiology. Insect control 


\section{REFERÊNCIAS BIBLIOGRÁFICAS}

1. ADAD, L. M. S. \& LIMA, M. G. F. Tensões sociais na zona rural piauiense. Carla CEPRO, Teresina, PI, 9: 19-30, 1983.

2. ALENCAR, J. E. Leishmaniose visceral no Novo Mundo. Publ. méd., Rio de Janeiro, 196: 71-85, 1956.

3. ALENCAR, J. E. Profilaxia do calazar no Ceará, Brasil Rev. Inst. Med. trop. S. Paulo, 3: 175-80, 1961.

4. ALENCAR, J. E. Leishmaniose visceral no Brasil. Rev. Med. Univ. Fed. Ceará, 17/18: 129-48, $1977 / 78$.

5. ALENCAR, J. E. Expansão do calazar no Brasil. Ceará méd., 5: 86-102, 1983.

6. ALENCAR, J. E.; DINIZ, J. O.; PESSOA FILHO, F. P.; ARAGĀO, T. C.; CORREIA, T. A. Alguns focos de calazar no Piauí. [Apresentado ao $13^{\circ}$ Congresso Brasileiro de Higiene, Fortaleza, 1956].

7. ALENCAR, J. E.; PESSOA, E. P.; COSTA, O. R. Calazar em Santarém, Estado do Pará, 1961. Rev. bras. Malar., 14: 371-7, 1962.

8. ALENCAR, J. E.; ALMEIDA, Y. M.; SILVA, Z. F.; PAIVA, A. S.; FONSECA, M. F. Aspectos atuais do calazar no Ceará. Rev. bros. Malar., 26/27: 27-33. $1974 / 75$.

9. ALVIM, M. G.; ALVIM, A. C.; ALVIM, M. O. B.; VALE, J. J. F. Situação atual do calazar na Ilha de São Luiz, Estado do Maranhão. Rev. Soc. bras. Med. trop., 19 (Supl.): 73, 1986.

10. AMÂNCIO, O. M. E. Requerimentos nutricionais. In: Nóbrega, F. J. Desnutrição intra-uterina e pós-natal. São Paulo, Panamed, 1981. p. 17-9.

11. ANUÁRIO ESTATÍSTICO DO BRASIL. (Fundação IBGE). Rio de Janeiro, 1951-1986. v. 11-47.

12. BACELAR, O. I. B. Fluxos migratórios e crescimento urbano piauiense. Carta CEPRO, Teresina, PI, 6: 25 $35,1980$.

13. BADARÓ, R.; CARVALHO, E. M.; ORGE, M. G. O.; TEIXEIRA, R.; ROCHA, H. Imunidade humoral e celular em indivíduos curados de leishmaniose visceral. Rev. Soc. bras. Med. trop.; 18: 77-83, 1985.

14. BADARÓ, R.; JONES, T. C.; LOURENÇO, R.; CERF, B. J.; SAMPAIO, D.; CARVALHO, E. M.; ROCHA H.; TEIXEIRA, R.; JOHNSON Jr, W. D. A prospective study of visceral leishmaniasis in endemic area of Brazil. J. infect. Dis., 154: 639-49, 1986.

15. BADARÓ, R.; JONES, T. C.; SAMPAIO, D.; REND, S. G.; BARRAL, A.; TEIXEIRA, R.; JOHNSON Jr., W.D. New perspective on a subclinical form of visceral leishmaniasis. J. infect. Dis.,154: 1003-11, 1986.

16. BANDEIRA, W. J. \& NEVES, O. C. Organização da produção agropecuária piauiense. Carta CEPRO, Teresina, PI, 8: 5-57, 1982.

17. BAPTISTA, J. G. Geografia física do Piaui. Teresina,
COMEPI, 1981.

18. BRADLEY, F. J. Genetics of resistence to infection with special reference to leishmaniasis. Introduction, and genetics of susceptibility to Leishmania donovani. Trans. roy. Soc. Trop. Med. Hyg., 76: $134-46,1982$.

19. CHANDRA, R. K. Immunocompetence in undernutrition. Trop. Ped., 81: 1194-200, 1972.

20. DEANE, L. M. Epidemiologia e profilaxia do calazar americano. Rev. bras. Malor., 10: 431-49, 1958.

21. DEANE, L. M. Reservatórios de Leishmania donovani no Brasil. Rev. Ass. méd. bras., 7: 161-9, 1961.

22. DEANE, L. M. \& DEANE, M. P. Encontro de leishmanias nas vísceras e na pele de uma raposa, em zona endêmica de calazar, nos arredores de Sobral, Ceará. Hospital, Rio de Janeiro, 45: 419-21, 1954.

23. DEANE, L. M. \& DEANE, M. P. Encontro de cães naturalmente infectados pela Leishmania donovani, no Ceará. Hospital, Rio de Janeiro, 45: 703-7, 1954.

24. DEANE, L. M. \& DEANE, M. P. Observações preliminares da importância comparativa do homem, do cão e da raposa (Lycalopex vetulus) como reservatórios de Leishmania donovani, em área endêmica de calazar, no Ceará. Hospital, Rio de Janeiro, 48 : $61-7,1955$.

25. DEANE, L. M. \& DEANE, M.P. Observaçōes sobre abrigos e criadouros de flebótomos no noroeste do Estado do Ceará. Rev. bras. Malar., 9: 225-46, 1957.

26. DEANE, L. M. \& DEANE, M. P. Visceral leishmaniasis in Brazil: geographical distribution and transmission. Rev. Inst. Med. trop. S. Paulo, 4: 198212, 1962.

27. DEANE, L. M. \& DEANE, M. P. Leishmaniose visceral urbana (no cão e no homem) em Sobral, Ceará. Hospital, Rio de Janeiro, 47: 75-87, 1985.

28. DEANE, L. M.; DEANE, M. P.; ALENCAR, J. E. Tipo de região e prevalência de leishmaniose visceral em uma região endêmica do Ceará. Rev. paul. Med., 46: $130-1,1955$.

29. DEANE, L. M.; DEANE, M. P.; ALENCAR, J. E. Observaçōes sobre o combate ao Phlebotomus longipalpis pela dedetização domiciliária, em focos endêmicos de calazar no Ceará. Rev. bras. Malar., 7: $131-41,1955$.

30. DEANE, M. P. \& DEANE, L. M. Infecção natural do Phlebotomus longipapis por leptomonas, provavelmente Leishmania donovani, em um foco de calazar no Ceará. Hospital, Rio de Janeiro, 45: 697-702, 1954

31. DE LA LOMA, A.; ALVAR J., J.; MARTINEZ GALIANO, E.; BLÁZQUES, J.; ALCALÁ MUNOOZ, A.; MÁJERA, R. Leishmaniasis or AIDS? Trans. roy. Soc. trop. Med. Hyg., 79: 421-2, 1985. 
32. DINIZ, J. A. F. A área centro-ocidental do Nordeste. Recife, SUDENE, 1982.

33. DOMINGOS NETO, M. \& NORGES, G. A. Seca seculorum, flagelo e mito na economia rural piauiense. Teresina, Fundação CEPRO, 1987.

34. DOOREMBAS, J. \& PRUIFF, W. O. Las necesidades de agua de los cultivos. Roma, FAO, 1976.

35. FOX, J. P.; ELVEBACK, L.; SCOTT, W.; GATEWOOD, L; ACKERMAN, E. Herd immunity: basic concepts and relevance to public health immunization practices. Amer. J. Epidem., 94: 179-89, 1971.

36. FUNDAÇĀO IBGE. Censo demográfico; dados distritais: Piaul. Rio de Janeiro, 1982. v. 1, t.3, n. 6. ( $9^{\circ}$ Recenseamento Geral do Brasil, 1980).

37. HARGREAVES, G. H. Precipitation dependabillity and potentials for agricultural production in Northearn Brazil. Logan, Utah State University, 1974.

38. HO, M.; SIONGOK, T. K.; LYERLY, W. H.; SMITH, D. H. Prevalence and disease spectrum in a new focus of visceral leishmaniosis in Kenya. Trans, roy. Soc. trop. Med. Hyg., 76: 741-6, 1982.

39. LILIENFELD, A. M. \& LILIENFELD, D. Foundation of epidemiology. New York, Oxford University Press, 1980.

40. MANSON-BAHR, P. E. C. Immunity in kala-azar. Trans. roy. Soc. trop. Med. Hyg., 55: 550-5, 1961.

41. MARTINS, A. S.; SILVA, A. B.; CRUZ, C. T.; MEDEIROS, A. J. C. B.; OLIVEIRA, F. M.; ROCHA, J.; FERREIRA NETO, J. F.; DOMINGOS NETO, $M$. Análise estrutural do Piauí: indústria, comércio e setor externo. Carta CEPRO, Teresina, PI, 8: 70 . 103, 1982.

42. MARZOCHI, K. B. F.; CALDERON, J. M. L.; BONFIM, M. L. Calazar no Brasil: problema em ascensão. Ars Curandi, 19: 139-44, 1986.

43. MELO, M. L. O meio-norte. Recife, SUDENE, 1983.

44. ORGANIZACION MUNDIAL DE LA SALUD. Comite de Expertos en las Leishmaniasis, Geneva, 1982. In- forme. Geneva, 1984. (Série de Informes Técnicos, 701).

45. PAMPIGLIONE, S.; MANSON-BAHR, P. E. C.; GIUNGI, F.; GIUNTI, G.; PARENTI, A.; CANESTRI TROTTI, G. Studies on Mediterranean leishmaniasis. 2 - Asymptomatic cases of visceral leishmaniasis. Trans. roy. Soc. trop. Med. Hyg., 68: 447 . 53, 1974.

46. PENNA, H. A. Leishmaniose visceral no Brasil. Brasil med., 48: 949-50, 1934.

47. SENALPI, G.; CADEO, G.; CARNEVALE, G.; DI PERRI, G.; CAROSI, G. Visceral leishmaniasis as an opportunistic infection. Lancet, 1: 1094, 1986.

48. SENRA, M. S.; PIMENTEL, P. S. R.; SOUZA, P. E. F. $P$. Leismaniose visceral em Santarém/PA: aspectos gerais do controle, inquérito sorológico em cães e tratamento de casos humanos. Rev. bras. Malar., 17: 47-59, 1985.

49. SHERLOCK, I. A. \& ALMEIDA, S. P. Observações sobre o calazar em Jacobina, Bahia. II - Leishmaniose canina. Rev. bras. Malar.; 21: 535-9, 1969.

50. SHERLOCK, I. A. \& GUITTON, N. Observaçōes sobre o calazar em Jącobina. Bahia. III - Alguns dados sobre Phlebotomus longipalpis, o principal transmissor. Rev. bras. Malar., 21: 541-8, 1969.

51. VASCONCELOS, P. C. B. Distribuição da população urbana de Teresina por bairro em 1985. Planejando Teresina, 1: 9-10, 1986.

52. WARD, D. M.; RIBEIRO, A. L.; READY, P. D.; MURTAGH, A. Reproductive isolation between different forms of Lutzomyia longipalpis (Lutz \& Neiva) (Diptera: Psychodidae); the vector of Leishmania donovani chagasi (Cunha \& Chagas) and its significance to kala-azar distribution in South America. Mem. Inst. Oswaldo Cruz, Rio de Janeiro, 78: 269 $80,1983$.

Recebido para publicaçäo em 9/11/1989 Reapresentado em 4/7/1990 Aprovado para publicação em 5/7/1990 